\title{
1 Biparental age effects in the burying beetle Nicrophorus vespilloides
}

$4{ }^{1}$ Institute of Evolutionary Biology, School of Biological Sciences, University of Edinburgh, Edinburgh,

5 EH9 3JT, UK

6

$7 \quad$ *Corresponding author. Email: jacob.moorad@ed.ac.uk

9 Keywords: Ageing, senescence, paternal, maternal 


\section{Abstract}

28 Parental age at reproduction influences offspring size and survival by affecting prenatal and

29 postnatal conditions in a wide variety of species, including humans. However, most

30 investigations into this manifestation of ageing focus upon maternal age effects; the effects of

31 paternal age and interactions between maternal and paternal age are often neglected.

32 Furthermore, even when maternal age effects are studied, pre- and postnatal effects are

33 confounded. Using a cross-fostered experimental design, we investigated the joint effects of

34 paternal and pre- and postnatal maternal ages on numerous offspring outcomes in a

35 laboratory population of a species of burying beetle, Nicrophorus vespilloides. When we

36 correct our tests for significance for multiple comparisons, we found no clear evidence for any

37 parental effect senescence acting on egg size, larval weight, or larval survival. Nor did we find

38 a statistical effect of paternal or egg producer age on the outcomes of foster mothers as

39 measured by weight change experienced during caregiving. These findings are consistent with

40 recent negative results reported in a similar study of $N$. vespilloides maternal age effects while

41 also expanding these to other offspring traits and to paternal age effects. We discuss how the

42 peculiar life history of this species may promote selection to resist the evolution of parental age effects, and how this might have influenced our ability to detect senescence. 


\section{Introduction}

45 Senescence is broadly defined as the progressive loss of function due to the accumulation of damage with age and is typically associated with declining fertility and survival, known respectively as reproductive and actuarial senescence (Finch et al. 1990; Monaghan et al. 2008; Jones et al. 2014). To date, a number of comprehensive studies have reported the wide taxonomic variation in patterns of reproductive and actuarial senescence across the tree of life (Promislow 1991; Gaillard et al. 1994; Jones et al. 2008; Nussey et al. 2008; Jones et al. 2014; Lemaître and Gaillard 2017). These perspectives tend to consider only the relationship between age and outcome within individuals. However, recent attention has begun to focus upon how the age of one individual affects the phenotype of another with a specific emphasis placed upon the effects of parental age upon offspring.

Most of this research focuses upon maternal ageing, or the tendency for offspring performance to change as maternal age increases. The best-known manifestations of maternal senescence, or age-related performance declines, take the form of negative associations between maternal age two offspring outcomes: lifespan and juvenile survival. The first is known as the 'Lansing effect' (Lansing 1947; Comfort, A 1953; Monaghan et al. 2020); while anecdotal evidence appears to suggest that this is a common pattern across species (see Table 1 from Monaghan et al. 2020), no formal review has yet assessed its prevalence. On the other hand, maternal senescence expressed as age-related declines in juvenile survival does appear to occur more frequently than not in suitably investigated animal species groups, with the notable exception of birds (Ivimey-Cook and Moorad 2020). However, for these and other traits, great variation appears across species in both the direction and magnitudes of maternal age effects. Predictive evolutionary theory does offer some explanation for variation in maternal age effects manifested on juvenile survival (Moorad and Nussey 2016), but has not yet been generalized to explain formally the evolution of the Lansing Effect or other types of maternal senescence. 
Paternal age effects are much less studied than maternal age effects (Lemaître and

Gaillard 2017), likely owing to the absence of post-zygotic paternal investment in most taxa which may reduce the opportunity for fathers to influence offspring (Kokko and Jennions 2008).

Nonetheless, paternal age effects have been shown to exist in both human (Kong et al. 2012)

and animal populations (Priest et al. 2002; Preston et al. 2015; Fay et al. 2016; Vuarin et al.

2019; Vuarin et al. 2021), with the majority showing similar detrimental effects as with maternal

ageing. As a result, we may also expect comparable patterns in both juvenile survival and

offspring adult lifespan across taxonomic groups, however no formal reviews have yet been conducted (although see Table 1 Monaghan et al. 2020). Our theoretical understanding of the

evolution of paternal senescence lags behind that of maternal senescence, as no such models have yet been proposed.

A fuller understanding of parental age effects comes from simultaneously investigating the joint effects of both paternal and maternal age (Laaksonen et al. 2002; Priest et al. 2002; Auld and Charmantier 2011; Torres et al. 2011; Ducatez et al. 2012; Auld et al. 2013; Bouwhuis et al. 2015; Brommer et al. 2015; Preston et al. 2015; Fay et al. 2016; Whelan et al. 2016; Vuarin et al. 2021). When biparental ages are varied at least semi-independently, then maternal-by-paternal age interactions can be resolved, and this can tell us how ageing in one parent can dampen or amplify the effect of age in the other (Auld and Charmantier 2011; Ducatez et al. 2012; Auld et al. 2013; Bouwhuis et al. 2015; Whelan et al. 2016). The joint effects of biparental ageing are occasionally characterized in terms of the difference between parental ages, or PADs (parental age differences) (Fieder and Huber 2007; Helle et al. 2008; Tidière et al. 2018). The effects of PADs are related to the main and interaction effects of biparental age as $\beta_{z, P A D}=\beta_{z, M}-\beta_{z, F}-\beta_{z, M \times F}$, where $z$ is offspring performance and $\beta$ indicates the effect upon $z$ caused by differences in male $(M)$ or female $(F)$ age. From this, we can see that the effects of PADs are inflated relative to the differences in parental and maternal age effects when there is a negative interaction between the two, as you might expect when there is some sort of compensation for the effects of age by one parent by the other. 
when the ageing of one parent 'poisons' the offspring regardless of the age of the other parent.

Despite several studies finding no significant effects of biparental ageing (Auld and

Charmantier 2011; Auld et al. 2013; Bouwhuis et al. 2015), several others have highlighted the advantages of studying maternal-by-paternal age interactions. For instance, male and female ages were found to interact and advance lay date, with older males buffering the detrimental effect of reduced female experience in a population of Grey jays (Perisoreus canadensis, Whelan et al. 2016). In addition, in another invertebrate species, Pieris brassicae, male and female age at laying interacted to increase and exacerbate delays in offspring development (Ducatez et al. 2012).

In this study, we investigate the joint effects of biparental ageing on the performance Nicrophorus vespilloides, a species of burying beetle that demonstrates biparental care. Burying beetles are useful laboratory systems for studying parental effects because the larvae are highly amenable to cross-fostering and for this reason, the experimenter is easily able to disentangle the effects of egg-producers and carers (Lock et al. 2007: 200; Ivimey-Cook and Moorad 2018). In addition, experimental removal of one parent appears to not detrimentally affect offspring performance with females able to fully compensate for male absence (Smiseth et al. 2005). Previous work involving N. vespilloides has found mixed evidence of parental age effects. Some studies have found that increased maternal age at reproduction had a detrimental effect on a number of larval traits (Ward et al. 2009; Cotter et al. 2011), however a more recent paper, which disentangled egg and carer contributions, found no effect of age acting on any of the measured offspring traits (see Ivimey-Cook and Moorad 2018). Here we replicate this previous study design while expanding it to survey more offspring traits (egg length and width) and to investigate pre-natal paternal age effects (reflecting age-related differences in sperm quality or carcass preparation). This design also allows us to estimate two distinct forms of maternal-by-paternal age interaction (pre-/post-natal maternal age $\mathrm{x}$ paternal age). In total, we were able to investigate five different sources of parental age effects (three main effects and two interaction effects). 


\section{Materials and Methods}

127

128

129

130

131

132

133

134

135

136

137

138

139

140

141

142

143

144

145

146

147

148

149

150

151

152

\section{Study species}

$N$. vespilloides breed on carcasses of small vertebrates and display elaborate forms of parental care (Scott 1998). Upon acquiring a carcass, a mating pair prepare it for breeding by burying it, removing all fur, scales, or feathers, rolling the carrion into a ball, and treating it with antimicrobial secretions (Smiseth et al. 2006). The female then lays eggs in the nearby soil. Newly hatched larvae aggregate on the carcass, where they both self-feed and are provisioned with pre-digested carrion by their parents, although typically the female is more involved with offspring care than the male (Smiseth et al. 2005). Parents care for their offspring until the larvae disperse from the carcass around five days after hatching. The beetles used in this experiment were bred from a large, outbred stock population maintained at the University of Edinburgh. The stock population derives exclusively from a wild population sampled from Corstophine Hill in Edinburgh, UK in 2016, and the experiment was performed in 2017. When not breeding, adults were housed individually in clear plastic containers $(12 \mathrm{x}$ $8 \times 2 \mathrm{~cm}$ ) filled with moist soil, at $20^{\circ} \mathrm{C}$, with a $16: 8$ light: dark photoperiod, and fed twice a week with raw organic beef.

\section{Experimental procedures}

Female (pre- and post-natal) and male age at first reproduction were classed as either "Young" or "Old" (11-18 days or 52-65 days post-eclosion to adulthood). These age classes were chosen as they have differing levels of cumulative survival ( $94 \%$ and $26 \%$ respectively, Moorad, personal communication), presumably leading to highly disparate intensities of selection for age-specific maternal effects that should favour the evolution of maternal senescence (Moorad and Nussey 2016). Sexual maturity is reached at around 10 days posteclosion (Lock et al. 2007). Older ages were not used here due to the scarcity of beetles surviving beyond 65 days. Varying the age at reproduction for the egg-producer, the father, and the carer, resulted in a three-factor design with eight treatment groups (Table S2). We set 
up a total of 154 matings; 142 of these produced eggs, and 106 produced larvae. We selected

15474 of these mothers to care for a brood, of these, 73 successfully raised larvae, and one carer

155 destroyed hers during the care period.

156 We weighed each outbred breeding pair (these included all combinations of male and

157 females ages (pre- and post-natal components), see Table 1) before transferring them to a breeding box $(17 \times 12 \times 6 \mathrm{~cm})$ with $2 \mathrm{~cm}$ of moist soil containing two small mice carcasses

159 (combined weight 17.59-25.63g) (Livefood Direct Ltd, Sheffield, UK). By providing the breeding pair with two carcasses, we expected high rates of egg and larvae production. As we describe below, one of these mice was removed from each pair to inflate larval density

162 (see below for justifications). For each carcass pair, we marked the carcass that deviated most from the average weight of the block by removing its tail. This allowed us to reduce the amongbrood variation in remaining carcass size below that of the original pool of mice. In all cases, the beetles prepared both carcasses by rolling them together into a ball.

Egg size

We measured individual egg sizes by acquiring an image of the eggs laid three days after mating (when egg laying had ceased) through the bottom of the transparent breeding box using a Canon ConoScan 9000F Mark II (Canon Inc., Tokyo, Japan). We assigned every visible egg in each image with a unique Egg ID and measured its length and perpendicular width using 600x magnification in the dedicated software ImageJ 1.50i (Schneider et al. 2012).

173 After all eggs were measured once, we repeated the process to assess the repeatability of 174 measurements. Overall, both the length and width of 1205 eggs were measured twice (Table 175 S1), resulting in 4820 measurements. The correlations between first and second 176 measurements of each egg were high (Spearman's $\rho=+0.90$ for length and +0.78 for width),

177 indicating highly repeatable measurements. 
Females were weighed immediately after scanning eggs (three days post-mating, see section above) to establish an initial weight for each female prior to providing care to offspring.

182 Females were then transferred along with the unmarked carcass to new breeding boxes that were absent of eggs. We disposed of the marked carcasses and the males (as we did not assess post-natal paternal age effects). Each breeding box that contained eggs was checked regularly for hatched larvae. We pooled larvae from same-aged egg-producer and paternal age groups (e.g. all offspring from young egg-producers and young fathers were pooled together) to construct mixed broods of 15 larvae. These were then provided to unrelated female carers of the either the same or differing age class. A standardized brood size of 15 was chosen as this represents a high but biologically reasonable number of larvae to be maintained on an 8.06-12.95g carcass. This represents approximately twice the density (approximately 1.1 larvae per gram of mouse rather than 0.6 larvae per gram) used in a previous N. vespilloides study of maternal senescence (Ivimey-Cook and Moorad 2018) and $50-100 \%$ greater density used in a N. vespilloides study of paternal senescence (Benowitz et al. 2013). We did this to increase the environmental stress placed upon offspring and carers, as evidence suggests that more stressful conditions can exacerbate the deleterious effects of age upon survival (Lemaître et al. 2013; Tidière et al. 2016) and reproductive output (Lemaître and Gaillard 2017). For this reason, we expected that our density manipulation would enhanced our ability to detect maternal senescence.

Larval disperse and pupate once the carcass is consumed. At this point, we counted and weighed each larva individually. The weight of larvae at dispersal is one measure believed to indicate the degree of parental reproductive investment (Ward et al. 2009). Female carers were also weighed a dispersal, and these measures were compared to those taken immediately after egg laying. The weight change of the carer over the caring period is believed to be an indicator of female investment in this species (Creighton et al. 2009; Billman et al. 2014). We then transferred post-care females to individual boxes where they were checked for death three times a week. This was to allow us to correct for selective disappearance of carers statistically by including carer age-of-death as a factor in our models. 
209 Statistical analyses

210 The experimental design required differently structured statistical models for different traits

211 (summarized in Table 1). These were we either univariate or bivariate linear mixed-models

212 analysed in ASReml 4.1 (Gilmour et al. 2015). The degree and nature of replication depended

213 upon the specific traits. Egg length and width observations were made twice for each egg

214 (2410 observations). Larval weight at dispersal was measured once for each offspring (697

216 (73 observations). All main effects and two-way interactions between the egg-producer,

217 paternal, and carer ages were included when biologically appropriate.

218

219 Table 1. Multivariate models used for data analysis

\begin{tabular}{|c|c|c|c|c|c|}
\hline Trait & Model number & Parental age (fixed & & effects $\dagger$ & Replicatesł \\
\hline Egg length & 1 & 1. Egg-producer & 1. & Block & $n=2410$ \\
\hline Egg width & & 2. Father & 2. & Egg-producer & $Y Y=818$ \\
\hline & & 3. Egg-producer X Father & ID & & $Y O=752$ \\
\hline & & & 3. & Egg ID & $\mathrm{OY}=370$ \\
\hline & & & & & $\mathrm{OO}=470$ \\
\hline
\end{tabular}

\begin{tabular}{|c|c|c|c|c|}
\hline Larval weight 2 & 1. Egg-producer & 1. & Block & $n=697$ \\
\hline \multirow[t]{8}{*}{ at dispersal } & 2. Father & 2. & Carer ID & $Y Y Y=114$ \\
\hline & 3. Carer & & & $Y Y O=73$ \\
\hline & 4. Egg-producer X Father & & & YOY = 88 \\
\hline & 5. Egg-producer X Carer & & & $\mathrm{YOO}=63$ \\
\hline & 6. Father X Carer & & & OYY = 83 \\
\hline & & & & OYO = 103 \\
\hline & & & & $\mathrm{OOY}=90$ \\
\hline & & & & $\mathrm{OOO}=83$ \\
\hline
\end{tabular}




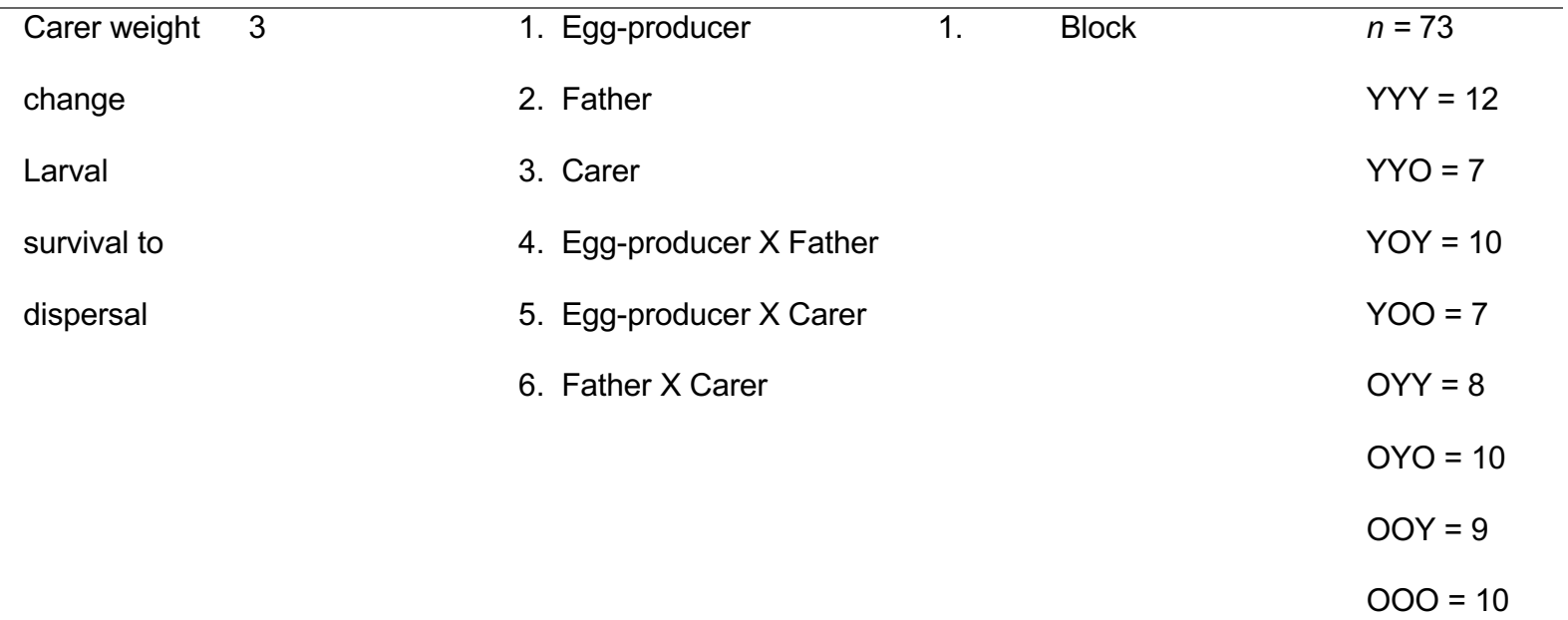

*As carcass size is known to affect larval fitness and egg production (Müller et al. 1990; Trumbo 1990), all models also included carcass weight and carcass weight ${ }^{2}$ as fixed effects. The combined weight of the two carcasses was used in the model to predict egg size, and the weight of the retained carcass was used for models predicting larval and carer outcomes.

†ID effects were nested within block effects, and the effects of egg IDs were nested within the effects of eggproducer IDs to account for possible pseudo-replication.

‡Sample sizes are given as the total number in each analysis and as each individual age combination. Ages are in the order of egg-producer, father, and carer.

Model 3 failed to converge initially and indicated a non-positive definite variancecovariance structure for block effects. In a similar manner to Ivimey-Cook and Moorad (2018), we ran univariate analyses for each female trait with and without the random effect of block to see if we could justify dropping this random effect from the full bivariate model. Likelihood ratio tests failed to find an effect of block upon the number of larvae surviving to dispersal $(P=$ 0.906), but they found a significant effect of blocks on carer weight change rerunning the full model while including block effects only for carer weight change $(P=0.004)$. We used these results to drop block effects on larval survival from our bivariate model (see Table S4 for likelihood ratio test results).

Longitudinal age-related declines in reproductive performance can be masked by selective disappearance of poor-quality individuals from the population. This effect has been reported in studies of ageing in red deer (Cervus elaphus) (Nussey et al. 2011), Soay sheep

233 (Ovis aries) (Hayward et al. 2013) and reindeer (Rangifer tarandus) (Weladji et al. 2008). 
However, this effect can be corrected for by including age of death as a covariate (van de Pol and Verhulst 2006; Nussey et al. 2011). Following Ivimey-Cook and Moorad (2018), we included carer age at death as a factor according to the interval during which death occurred. In this study, age had two levels: (1) between "Young" and "Old" age classes and (2) post "Old" age class. The inclusion of carer age of death into statistical models allowed us to correct for the effects of selective disappearance of carers, but not egg-producers or males, as the use of mixed broods prevented identification of genetic parents.

\section{Results}

243 For brevity, only the model results for fixed age effects are provided here. Full model results are given as indicated below in the Supplemental section. z-scores were calculating by dividing effect sizes by standard errors, and $p$ values were calculated from these. Effect sizes were divided by the median difference between the "Young" and "Old" age groups (44 days) to calculate per-day effect sizes. Significance was taken at $\alpha=0.05$. However, we note that the models estimated 27 effects of age (main and interaction effects), and a Bonferroni correction indicated a threshold for significance of $p=1.85 \times 10^{-3}$. No estimated effect of age reached that threshold.

Parental age effects on egg length and width

253 Old egg-producers and fathers produced eggs that were longer and narrower in comparison to young parents, but these effects did not reach statistical significance (Table 2). Interactions between egg-producer and father ages were negative but significantly less than zero only for effects on egg length. Differently put, matching the ages of the egg-producer and father was associated with decreased egg length. While the main effects of both parental ages were nonsignificant for this trait, it did appear that the matching ages of both the egg-producer and father produced significantly shorter eggs. 
261 Table 2. The effects of egg-producer and father age on egg size. The units of egg length and

262 width are in $\mathrm{mm}$. Effects that were significant to a threshold of $\alpha=0.05$ are in boldface. Full

263 model results are given in Table S5.

\begin{tabular}{|c|c|c|c|c|c|}
\hline Egg trait & Covariate & $\begin{array}{l}\text { Effect size } \\
\left(10^{-3} \mathrm{~mm} / \text { day }\right)\end{array}$ & Standard errors & z score & $p$ \\
\hline \multirow[t]{3}{*}{ Length } & Egg-producer age & 0.781 & 0.515 & 1.515 & 0.130 \\
\hline & Father age & 0.179 & 0.445 & 0.402 & 0.688 \\
\hline & Egg-producer age*father age & -1.551 & 0.690 & -2.246 & 0.025 \\
\hline \multirow[t]{3}{*}{ Width } & Egg-producer age & -0.053 & 0.446 & -0.118 & 0.906 \\
\hline & Father age & -0.044 & 0.392 & -0.113 & 0.910 \\
\hline & Egg-producer age*father age & -0.580 & 0.596 & -0.974 & 0.330 \\
\hline
\end{tabular}

264

Parental age effects on larval weight at dispersal

266 Larval weight decreased with increased age of the egg producer, the father, and the carer. All

267 two-way interaction effects were positive, larval weight increased with when both parental 268 ages increased, but none were statistically significant (Table 3, Figure S2).

270 Table 3. The effects of egg-producer, father, and carer age on larval weight at dispersal. Full

271 model results are given in Table S6.

\begin{tabular}{|c|c|c|c|c|}
\hline Covariate & $\begin{array}{l}\text { Effect size } \\
\text { (mg/day) }\end{array}$ & $\begin{array}{l}\text { Standard errors } \\
\text { (mg/day) }\end{array}$ & z score & $p$ \\
\hline Egg-producer age & -0.503 & 0.316 & -1.591 & 0.112 \\
\hline Father age & -0.216 & 0.301 & -0.718 & 0.472 \\
\hline Carer age & -0.270 & 0.323 & -0.834 & 0.404 \\
\hline Egg-producer age*father age & 0.235 & 0.375 & 0.627 & 0.530 \\
\hline Egg-producer age ${ }^{*}$ carer age & 0.254 & 0.375 & 0.677 & 0.498 \\
\hline Father age* carer age & 0.075 & 0.369 & 0.204 & 0.838 \\
\hline Age of carer at death & -0.814 & 0.800 & -1.017 & 0.309 \\
\hline
\end{tabular}

272

273 Parental age effects on carer traits, carer weight change and larval survival to dispersal 
274 Old carers gained more weight than young carers during the parental care period. However,

275 both old fathers and old egg-producers produced larvae that caused carers to gain less weight.

276 All possible two-way interaction effects were positive, but none of the main or interaction

277 effects were statistically significant to $\alpha=0.05$. Larval survival increased with all three main

278 effects of age, but only the main effect of egg-producer age was statistically significant to the

279 uncorrected level of significance. All two-way interactions were negative, with the interaction

280 of egg-producer and carer ages significant to the uncorrected level of significance (Table 4,

281 Figure S3-S4).

282

283 Table 4. Effects of egg-producer, father, and carer age on carer weight change and larval

284 survival. Units are $m g$ for weight change measurements, and larval survival is given in terms

285 of a fraction (\#survived divided by 15 for the initial brood size). Full model results are given in

286 Table S7.

287

\begin{tabular}{|c|c|c|c|c|c|}
\hline Trait & Covariate & $\begin{array}{l}\text { Effect size } \\
\text { (unit/day) }\end{array}$ & $\begin{array}{l}\text { Standard errors } \\
\text { (unit/day) }\end{array}$ & z score & p value \\
\hline \multirow[t]{9}{*}{ Carer weight change } & Egg-producer age & -0.160 & 0.344 & -0.466 & 0.641 \\
\hline & Father age & -0.008 & 0.266 & -0.032 & 0.975 \\
\hline & Carer age & 0.108 & 0.370 & 0.293 & 0.770 \\
\hline & Egg-producer age*father age & 0.195 & 0.383 & 0.509 & 0.611 \\
\hline & Egg-producer age*carer age & 0.157 & 0.394 & 0.399 & 0.690 \\
\hline & Father age* carer age & 0.143 & 0.345 & 0.414 & 0.679 \\
\hline & Age of carer at death & -0.332 & 0.738 & -0.450 & 0.653 \\
\hline & Egg-producer age & 0.004 & 0.002 & 2.267 & 0.023 \\
\hline & Father age & 0.001 & 0.002 & 0.713 & 0.476 \\
\hline \multirow[t]{4}{*}{ Larval survival to dispersal } & Carer age & 0.003 & 0.002 & 1.807 & 0.071 \\
\hline & Egg-producer age*father age & -0.002 & 0.002 & -0.951 & 0.342 \\
\hline & Egg-producer age*carer age & -0.004 & 0.002 & -2.340 & 0.019 \\
\hline & Father age*carer age & -0.003 & 0.002 & -1.658 & 0.097 \\
\hline
\end{tabular}




\section{Discussion}

There is much evidence from laboratory studies of $N$. vespilloides to suggest that maternal condition influences offspring phenotypes (Paquet and Smiseth 2017; Mattey et al. 2018; Ratz et al. 2018), but a previous study (Ivimey-Cook and Moorad 2018) found that maternal quality did not appear to change with age. Our study (which was performed in the same laboratory as all aforementioned studies) largely replicated the results reported by Ivimey-Cook and Moorad (2018), as neither detected statistical support for a general tendency towards pre- and post-natal maternal ageing to be manifested on a suite of traits related to offspring and carer fitness. Furthermore, this study suggests that this insensitivity of parental quality to changes in age also apply to pre-natal attributes of the fathers (sperm quality), to another offspring trait expected to influence fitness (egg length and width), and to a more stressful environment (high larval density). Below, we discuss how estimates from our study relate to those from other comparable studies and why the life history of this species might explain why we cannot reliably detect signatures of parental senescence.

The size of eggs reflects the degree of maternal investment made into each egg (Bagenal 1969), and because egg size appears to predict the size of newly hatched in $N$. vespilloides larvae (Monteith et al. 2012; Steiger 2013), this may be an important determinant of juvenile survival. If the resources available to a mother (or the ability of the mother to use these resources effectively) decline with age owing to senescence, then we might expect that egg size should also decline with maternal age. A previous study of hatch weight in this species found a negative effect of maternal age (Lock et al. 2007), but here we found no significant effect of either parent's age on egg width and length. In contrast, bird studies have

312 reported maternal age-related increases in egg size (Weimerskirch 1992; Bogdanova et al. 313 2006). However, birds and insects may operate under very different constraints in terms of 
maternal investment in eggs, particularly in how they are subjected to size-number trade-offs that are expected to result from limited resources. In a smaller study (700 vs 1205 eggs), Monteith et al (2012) reported no evidence of a negative correlation between egg size and clutch size in $N$. vespilloides, and they suggested that this may be because the costs of egg production are small in this species owing to their small size relative to the mothers. Although parental age was not directly manipulated in that study, they included maternal age as a covariate in their models and found that it had no significant relationship with egg size. Lastly, we note that increasing the size of breeding resource had a significantly negative effect on egg length $(p=0.020$, Table S6). This could be in response to the perception by the female egg-layer that the environment was of higher quality, which would mean more resources for her larvae, and therefore less pressure to invest her own resources into her eggs. A similar pattern has been seen in several Daphnia species (Guisande and Gliwicz 1992), where egg size increases with decreasing food abundance.

Survival to dispersal is of obvious importance to fitness in this species, as successful dispersal is a necessary condition for survival to adulthood. The evolutionary theory of senescence has thus far been applied to maternal effects formally for only those traits that are important components of neonatal survival (Moorad and Nussey 2016), and this theory predicts that juvenile survival should decline at older maternal ages. However, the current study found positive effects of egg-producer and carer age on larval survival, although only the former was significantly different from zero. The direction and significance of both agree with results from an earlier study from the same laboratory. However, it should be noted that model specifications differed (the older study contained quadratic effects of age) owing to a different experimental design. We note that both studies detected a significant negative eggproducer-by-carer interaction effect on larval survival. With the caveat that models are structured in slightly different ways, both results suggest that larval survival increases with the age of both the egg producer and the carer, and the marginal increase in survival that a larva 
341

342

this should be, but one possibility is that there are diminishing returns associated with benefits of ageing that are delivered to the offspring.

We found negative, but non-significant effects of all carers', egg producers', and fathers' ages upon larval weight at dispersal. This trait predicts adult size, which is known to be an important factor in determining an adult's competitive ability for securing reproductive resources (Bartlett 1988) and, therefore, for fitness. Ivimey-Cook and Moorad (2018) also reported non-significant effects of carer age, but the effects of egg-producer age were more ambiguous. In a model with first-order relationships only, the main effect of age was negative and insignificant. In a model with quadratic terms, including age-squared, the linear effect of egg-producer age was significantly greater than zero. Ward et al. (2009) report significantly negative effects of increased maternal age on this trait, but their experimental design conflated age with parity. Furthermore, that study did not vary the ages of carers and egg-producers independently of one-another, and the per-day effect of maternal age $(-1.97 \mathrm{mg} / \mathrm{day}$, as derived by Ivimey-Cook \& Moorad (2018)) best represent the sum of pre- and post-natal age effects. If we assume no correlations between pre- and post-natal maternal effects in our study, then we can produce a similar measure by summing the two maternal effects, and we can synthesize a SE for that measure by taking the square-root of the summed squares of the individual SEs. From this, we arrive at a total maternal age effect estimate of $-0.77 \mathrm{mg} / \mathrm{day}$ with a SE of $0.80 \mathrm{mg} /$ day. These imply a $95 \%$-tile interval $(-2.025,0.479)$ that includes the estimate from Ward et al. (2009). The same exercise applied to the relevant estimates taken from Ivimey-Cook and Moorad (2018) yield (-0.951, 0.777), which includes the results presented here but not the results from Ward et al. We note, however, that the SEs estimated here are roughly half again as large as those reported by Ivimey-Cook and Moorad (2018), and this limits the power of this exercise to compare our results for combined maternal age effects with those from other studies. However, we can infer from our results that if these combined maternal age effects are deleterious with increased age, they are likely no more extreme than those reported by Ward et al. (2009). 
Lock et al. (2007) found no significant effect of the age of either the egg producer or the carer on larval weight gain. As initial larval mass is approximately two orders of magnitude smaller than weight at dispersal (Lock et al. 2007), we can take weight gain to be a reasonable proxy for the latter, and these results can be viewed as consistent with ours. The earlier study found a positive interaction effect between the ages of egg-producers and carers, which they interpreted as evidence for age-specific coadaptation for pre- and post-natal maternal effects. We also found a positive interaction, but that effect size was non-significant in our study. We note that this study used greater brood sizes than Lock et al. (2007) ( $n=15$ vs 9.3), which would mean more resources available to each individual offspring in the previous study.

There was no difference in the degree of weight loss between young and old carers during postnatal care. Nor did the age of the egg-producer or father appear to influence the traits of the carer. If the age of the genetic parents altered the burden placed upon the carer carer investment enough to be detected. Further insights gained through behavioural observations could also help explain the lack of age effects on carer outcomes, particularly if parental care behaviours are changing as a result of increasing egg-producer and father age. characteristics of the partner, it is important to consider any paternal age-effects on reproductive performance, but studies that investigate these are rare and show a diversity of results. We found that paternal age has no detectable effect on offspring quality in $N$. vespilloides; and this result is supported by Ward et al. (2009) who found no detectable effect upon mass at dispersal in this species. Fox et al. (2003) also found no evidence that paternal age affected any offspring traits in a study of the seed beetle Callosobruchus maculatus. However, Fay et al. (2016) found that the age of fathers in the wandering albatross, Diomedea exulans, significantly influenced offspring performance, with increasing paternal age leading to declines in juvenile survival. Paternal age in humans was shown to be the predominant factor behind the exponential increase in the number of de novo mutations occurring within children (Kong et al. 2012), and increased paternal age in the houbara bustard, Chlamydotis 
undulata, was found to decrease sperm quality and hatching success and to slow neonatal development (Preston et al. 2015). Conversely, male age in a different bird species, Colaptes auratus, was associated with increased clutch size, earlier laying and greater fledging success (Wiebe 2018). Results from the present study appear to support the notion that no clear patterns of directional effects exist.

The effects of differences between the age of father and mothers (parental age differences, or PADs) have received interest in studies of human reproduction, where they appear to predict family size (Fieder and Huber 2007; Helle et al. 2008). Tidière et al. (2018) recently pointed out, however, that the effects of PADs are statistically entangled with the main effects of parental age, and for this reason they recommend that single parent ages be used as covariates in analyses of PAD effects. We agree with this reasoning, but Tidière et al. (2018) leave out a statistically explicit definition of PADs that we provide here $\left(\beta_{z, P A D}=\beta_{z, M}-\beta_{z, F}-\right.$ $\beta_{Z, M \times F}$ ), where main and interaction effects can be estimated simultaneously by GLMs, as we have done here. As we have noted, we detected effects of interactions between father and egg-producer upon egg length in $N$. vespilloides. In this case, effect sizes estimates given in

411 Table 3 define the PAD effect to be equal to $0.949 \times 10^{-3} \mathrm{~mm} /$ day. Many other studies estimate parental-age-interaction effects (Laaksonen et al. 2002; Auld et al. 2013; Brommer et al. 2015;

413 Whelan et al. 2016), and these can be converted to define PAD effects in the same way to 414 provide a clearer perspective of causality.

Selective disappearance has been shown to be an important contributor to populationlevel ageing patterns in wild vertebrate systems (Nussey et al. 2006; Hayward et al. 2013),

417 but it is seldom investigated in laboratory studies of ageing. Our study controlled for selective disappearance of carers, but we found no evidence that mortality biased parental age effects.

419 Ivimey-Cook and Moorad (2018) also found no evidence for selective disappearance of carers.

420 Unfortunately, neither $N$. vespilloides study could investigate selective disappearance of egg 421 producers or father, as both experiments used mixed broods of larvae, and identification of 422 the genetic parents of larvae is not possible. Using intact broods of cross-fostered larvae, 
423 where larval siblings were cross-fostered to a non-related carer, would have allowed the age

424 of death of all three parents to be accounted for. However, a pilot study suggested that this

425 would be extremely difficult owing to both asynchronous hatching of larvae within a brood and

426 the high frequency of broods with small numbers of larvae. A further study using a larger

427 combined carcass size would, in theory, increase the number of eggs laid and larvae produced

428 by each breeding pair, and allow more successful cross-fostering of intact broods. In this way,

429 potential bias arising from selective disappearance of the other parents could be assessed,

430 too.

A recent review of the literature that examines maternal age effects on early survival

432 (Ivimey-Cook and Moorad 2020) found that among widely-studied taxa, insect species feature

433 the strongest tendencies towards maternal effect senescence (17 of 26 species exhibited

434 senescence). As our results show that maternal effect senescence is not manifested on

435 offspring traits; this suggests that $N$. vespilloides is unusual. This species has a peculiar life history that we suggest indicates an evolutionary cause for slowed (and, thus, harder to detect) rates of maternal effect senescence. Evolutionary theory demonstrates that selection for the maternal effects upon neonatal survival is proportional to the age distribution of maternal ages (Moorad and Nussey 2016). It follows that when reproduction is highly focused upon a small range of ages, then the decline in selection for maternal effects that follows the onset of reproduction will be dramatic, and evolution will favour extreme rates of ageing. When reproduction is spread over many ages, the opposite is expected: ageing should be gradual.

443 Reproduction in N. vespilloides depends upon the availability of vertebrate carcasses, and this 444 is a rare and unpredictable resource (Scott 1998). As a result, we can expect high variation in 445 the age of first reproduction and in the time between successive reproductive events. These 446 features will cause the shape of the frequency distribution of maternal ages at birth to favour 447 a late maximum (the age of strongest selection) and subsequent slow declines afterwards (a 448 slow rate of relaxing selection). The latter feature will promote strong selection to resist senescence in maternal age effects, which is consistent with the observations made here for 450 larval survival. Whilst the evolutionary theory makes explicit predictions regarding only 
451

452

453

454

455

456

457

458

459

460

461

462

463

464

465

466

467

468

469

470

471

472

473

474

475

476

477

478

479

480

481

482

483

maternal effects on neonatal survival, it seems reasonable to expect that similar predictions would apply both to other offspring traits and to paternal age effects, but the future models should be developed to generalize the theory to consider these other traits and factors.

\section{References}

Auld JR, Charmantier A. 2011. Life history of breeding partners alters age-related changes of reproductive traits in a natural population of blue tits. Oikos. 120(8):1129-1138. doi:10.1111/j.1600-0706.2010.19161.x.

Auld JR, Perrins CM, Charmantier A. 2013. Who wears the pants in a mute swan pair? Deciphering the effects of male and female age and identity on breeding success. Journal of Animal Ecology. 82(4):826-835. doi:10.1111/1365-2656.12043.

Bagenal TB. 1969. Relationship between Egg Size and Fry Survival in Brown Trout Salmo trutta L. Journal of Fish Biology. 1(4):349-353. doi:10.1111/j.1095-8649.1969.tb03882.x.

Bartlett J. 1988. Male mating success and paternal care in Nicrophorus vespilloides (Coleoptera: Silphidae). Behavioral Ecology and Sociobiology. 23(5):297-303.

Benowitz KM, Head ML, Williams CA, Moore AJ, Royle NJ. 2013. Male age mediates reproductive investment and response to paternity assurance. Proceedings of the Royal Society B: Biological Sciences. 280(1764). doi:10.1098/rspb.2013.1124.

Billman EJ, Creighton JC, Belk MC. 2014. Prior experience affects allocation to current reproduction in a burying beetle. Behavioral Ecology. 25(4):813-818. doi:10.1093/beheco/aru051.

Bogdanova MI, Nager RG, Monaghan P. 2006. Does parental age affect offspring performance through differences in egg quality? Functional Ecology. 20(1):132-141. doi:10.1111/j.1365-2435.2006.01088.x.

Bouwhuis S, Vedder O, Becker PH. 2015. Sex-specific pathways of parental age effects on offspring lifetime reproductive success in a long-lived seabird. Evolution. 69(7):1760-1771. doi:10.1111/evo.12692.

Brommer JE, Karell P, Aaltonen E, Ahola K, Karstinen T. 2015. Dissecting direct and indirect parental effects on reproduction in a wild bird of prey: dad affects when but not how much. Behavioral Ecology and Sociobiology. 69(2):293-302. doi:10.1007/s00265-014-1842-4.

Comfort, A. 1953. Absence of a Lansing Effect in Drosophila subobscura. Nature. 172:83-84.

Cotter SC, Ward RJ, Kilner RM. 2011. Age-specific reproductive investment in female burying beetles: Independent effects of state and risk of death. Functional Ecology. 25(3):652-660. 
484

485

486

487

488

489

490

491

492

493

494

495

496

497

498

499

500

501

502

503

504

505

506

507

508

509

510

511

512

513

514

515

516

517

518

519

520

Creighton JC, Heflin ND, Belk MC. 2009. Cost of reproduction, resource quality, and terminal investment in a burying beetle. The American Naturalist. 174(5):673-684.

doi:10.1086/605963.

Ducatez S, Baguette M, Stevens VM, Legrand D, Fréville H. 2012. Complex Interactions Between Paternal and Maternal Effects: Parental Experience and Age at Reproduction Affect Fecundity and Offspring Performance in a Butterfly. Evolution. 66(11):3558-3569. doi:10.1111/j.1558-5646.2012.01704.x.

Fay R, Barbraud C, Delord K, Weimerskirch H. 2016. Paternal but not maternal age influences early-life performance of offspring in a long-lived seabird. Proceedings of the Royal Society B: Biological Sciences. 283(1828):20152318. doi:10.1098/rspb.2015.2318.

Fieder M, Huber S. 2007. Parental age difference and offspring count in humans. Biology Letters. 3(6):689-691. doi:10.1098/rsbl.2007.0324.

Finch CE, Pike MC, Witten M. 1990. Slow mortality rate accelerations during aging in some animals approximate that of humans. Science. 249(4971):902-905. doi:10.1126/science. 2392680 .

Fox CW, Bush ML, Wallin WG. 2003. Maternal age affects offspring lifespan of the seed beetle, Callosobruchus maculatus. Functional Ecology. 17(6):811-820. doi:10.1111/j.13652435.2003.00799.x.

Gaillard J-M, Allaine D, Pontier D, Yoccoz NG, Promislow DEL. 1994. Senescence in Natural Populations of Mammals: A Reanalysis. Evolution. 48(2):509-516. doi:10.2307/2410110.

Gilmour AR, Gogel BJ, Cullis BR, Welham Sj, Thompson R. 2015. ASReml user guide release 4.1 structural specification. Hemel hempstead: VSN international Itd.

Guisande C, Gliwicz ZM. 1992. Egg size and clutch size in two Daphnia species grown at different food levels. Journal of Plankton Research. 14(7):997-1007. doi:10.1093/plankt/14.7.997.

Hayward AD, Wilson AJ, Pilkington JG, Clutton-Brock TH, Pemberton JM, Kruuk LEB. 2013. Reproductive senescence in female Soay sheep: Variation across traits and contributions of individual ageing and selective disappearance. Functional Ecology. 27(1):184-195.

doi:10.1111/1365-2435.12029.

Helle S, Lummaa V, Jokela J. 2008. Marrying women 15 years younger maximized men's evolutionary fitness in historical Sami. Biology Letters. 4(1):75-77. doi:10.1098/rsbl.2007.0538.

Ivimey-Cook E, Moorad J. 2020. The diversity of maternal-age effects upon pre-adult survival across animal species. Proc R Soc B. 287(1932):20200972. doi:10.1098/rspb.2020.0972.

Ivimey-Cook ER, Moorad J. 2018. Disentangling pre- and post-natal maternal age effects on offspring performance in an insect with elaborate maternal care. The American Naturalist. 192(5):564-576. 
521 Jones OR, Gaillard J-M, Tuljapurkar S, Alho JS, Armitage KB, Becker PH, Bize P, Brommer J,

522 Charmantier A, Charpentier M, et al. 2008. Senescence rates are determined by ranking on

523 the fast-slow life-history continuum. Ecology Letters. 11(7):664-673. doi:10.1111/j.1461-

524 0248.2008.01187.x.

525 Jones OR, Scheuerlein A, Salguero-Gómez R, Camarda CG, Schaible R, Casper BB, Dahlgren

526 JP, Ehrlén J, García MB, Menges ES, et al. 2014. Diversity of ageing across the tree of life.

527 Nature. 505(7482):169-173. doi:10.1038/nature12789.

528 Kokko H, Jennions MD. 2008. Parental investment, sexual selection and sex ratios. Journal of 529 evolutionary biology. 21(4):919-48. doi:10.1111/j.1420-9101.2008.01540.x.

530 Kong A, Frigge M, Masson G, Nature SB-, 2012 U. 2012. Rate of de novo mutations and the 531 importance of father's age to disease risk. Nature. 488(7412):471-475.

532 Laaksonen T, Korpimäki E, Hakkarainen H. 2002. Interactive effects of parental age and 533 environmental variation on the breeding performance of Tengmalm's owls. Journal of 534 Animal Ecology. 71(1):23-31. doi:10.1046/j.0021-8790.2001.00570.x.

535 Lansing Al. 1947. A transmissible, cumulative, and reversible factor in aging. Journal of 536 Gerontology. 2(3):228-239.

537 Lemaître J-F, Gaillard J-M. 2017. Reproductive senescence: new perspectives in the wild. 538 Biological Reviews. 92(4):2182-2199. doi:10.1111/brv.12328.

539 Lemaître J-F, Gaillard J-M, Lackey LB, Clauss M, Müller DWH. 2013. Comparing free-ranging 540 and captive populations reveals intra-specific variation in aging rates in large herbivores. 541 Experimental Gerontology. 48(2):162-167. doi:10.1016/j.exger.2012.12.004.

542 Lock JE, Smiseth PT, Moore PJ, Moore AJ. 2007. Coadaptation of Prenatal and Postnatal 543 Maternal Effects. The American Naturalist. 170(5):709-718. doi:10.1086/521963.

544 Mattey SN, Richardson J, Ratz T, Smiseth PT. 2018. Effects of offspring and parental 545 inbreeding on parent-offspring communication. The American Naturalist. 191(6):716-725. 546 doi:10.1086/697236.

547 Monaghan P, Charmantier A, Nussey DH, Ricklefs RE. 2008. The evolutionary ecology of 548 senescence. Functional Ecology. 22(3):371-378. doi:10.1111/j.1365-2435.2008.01418.x.

549 Monaghan P, Maklakov AA, Metcalfe NB. 2020. Intergenerational Transfer of Ageing: 550 Parental Age and Offspring Lifespan. Trends in Ecology \& Evolution. 35(10):927-937. 551 doi:10.1016/j.tree.2020.07.005.

552 Monteith KM, Andrews C, Smiseth PT. 2012. Post-hatching parental care masks the effects 553 of egg size on offspring fitness: A removal experiment on burying beetles. Journal of 554 Evolutionary Biology. 25(9):1815-1822. doi:10.1111/j.1420-9101.2012.02567.x. 
Moorad JA, Nussey DH. 2016. Evolution of maternal effect senescence. Proceedings of the National Academy of Sciences of the United States of America. 113(2):362-367. doi:10.1073/pnas.1520494113.

558 Müller JK, Eggert AK, Furlkröger E. 1990. Clutch size regulation in the burying beetle 559 Necrophorus vespilloides Herbst (Coleoptera: Silphidae). Journal of Insect Behavior. 560 3(2):265-270. doi:10.1007/BF01417917.

561 Nussey DH, Coulson T, Delorme D, Clutton-Brock TH, Pemberton JM, Festa-Bianchet M, 562 Gaillard J-M. 2011. Patterns of body mass senescence and selective disappearance differ 563 among three species of free-living ungulates. Ecology. 92(10):1936-1947. doi:10.1890/11564 0308.1.

565 Nussey DH, Coulson T, Festa-Bianchet M, Gaillard J-M. 2008. Measuring senescence in wild animal populations: towards a longitudinal approach. Functional Ecology. 22(3):393-406. doi:10.1111/j.1365-2435.2008.01408.x.

568 Nussey DH, Kruuk LEB, Donald A, Fowlie M, Clutton-Brock TH. 2006. The rate of senescence 569 in maternal performance increases with early-life fecundity in red deer. Ecology Letters. 570 9(12):1342-1350. doi:10.1111/j.1461-0248.2006.00989.x.

571 Paquet M, Smiseth PT. 2017. Females manipulate behavior of caring males via prenatal 572 maternal effects. Proceedings of the National Academy of Sciences of the United States of 573 America. 114(26):6800-6805. doi:10.1073/pnas.1619759114.

574 van de Pol M, Verhulst S. 2006. Age-dependent traits: a new statistical model to separate 575 within- and between-individual effects. The American Naturalist. 167(5):766-773.

576 doi:10.1086/503331.

577 Preston BT, Saint Jalme M, Hingrat Y, Lacroix F, Sorci G. 2015. The sperm of aging male 578 bustards retards their offspring's development. Nature Communications. 6(1):1-9. 579 doi:10.1038/ncomms7146.

580 Priest NK, Mackowiak B, Promislow DEL. 2002. The role of parental age effects on the 581 evolution of aging. Evolution. 56(5):927-935.

582 Promislow DEL. 1991. Senescence in Natural Populations of Mammals: A Comparative 583 Study. Evolution. 45(8):1869-1887. doi:10.1111/j.1558-5646.1991.tb02693.x.

584 Ratz T, Castel E, Smiseth PT. 2018. Male assistance in parental care does not buffer against 585 detrimental effects of maternal inbreeding on offspring. Frontiers in Ecology and Evolution. 586 6(NOV). doi:10.3389/fevo.2018.00196.

587 Schneider CA, Rasband WS, Eliceiri KW. 2012. NIH Image to ImageJ: 25 years of image 588 analysis. Nature Methods. doi:10.1038/nmeth.2089.

589 Scott MP. 1998. the Ecology and Behavior of Burying Beetles. Annual Review of Entomology. 590 43(1):595-618. doi:10.1146/annurev.ento.43.1.595. 

loss? Differential response by males and females. Animal Behaviour. 69(3):551-559. doi:10.1016/j.anbehav.2004.06.004.

594 Smiseth PT, Ward RJS, Moore AJ. 2006. Asynchronous hatching in Nicrophorus vespilloides, 595 an insect in which parents provide food for their offspring. Functional Ecology. 20(1):151596 156. doi:10.1111/j.1365-2435.2006.01072.x.

597 Steiger S. 2013. Bigger mothers are better mothers: disentangling size-related prenatal and 598 postnatal maternal effects. Proceedings of the Royal Society B: Biological Sciences. 599 280(1766):20131225-20131225. doi:10.1098/rspb.2013.1225.

600 Tidière M, Gaillard J-M, Berger V, Müller DWH, Bingaman Lackey L, Gimenez O, Clauss M, 601 Lemaître J-F. 2016. Comparative analyses of longevity and senescence reveal variable 602 survival benefits of living in zoos across mammals. Scientific Reports. 6(1):36361. 603 doi:10.1038/srep36361.

604 Tidière $M$, Thevenot X, Deligiannopoulou A, Douay G, Whipple M, Siberchicot A, Gaillard J605 M, Lemaître J-F. 2018. Maternal reproductive senescence shapes the fitness consequences 606 of the parental age difference in ruffed lemurs. Proceedings of the Royal Society B:

607 Biological Sciences. 285(1886). doi:10.1098/rspb.2018.1479.

608 Torres R, Drummond H, Velando A. 2011. Parental Age and Lifespan Influence Offspring 609 Recruitment: A Long-Term Study in a Seabird. Leonard ML, editor. PLoS ONE. 6(11):e27245. 610 doi:10.1371/journal.pone.0027245.

611 Trumbo ST. 1990. Regulation of brood size in a burying beetle, Nicrophorus tomentosus 612 (Silphidae). Journal of Insect Behavior. 3(4):491-500. doi:10.1007/BF01052013.

613 Vuarin P, Bouchard A, Lesobre L, Levêque G, Chalah T, Jalme MS, Lacroix F, Hingrat Y, Sorci 614 G. 2019. Post-copulatory sexual selection allows females to alleviate the fitness costs 615 incurred when mating with senescing males. Proc R Soc B. 286(1913):20191675. 616 doi:10.1098/rspb.2019.1675.

617 Vuarin P, Lesobre L, Levêque G, Saint Jalme M, Lacroix F, Hingrat Y, Sorci G. 2021. Paternal 618 age negatively affects sperm production of the progeny. Grether $\mathrm{G}$, editor. Ecology 619 Letters.:ele.13696. doi:10.1111/ele.13696.

620 Ward RJS, Cotter SC, Kilner RM. 2009. Current brood size and residual reproductive value 621 predict offspring desertion in the burying beetle Nicrophorus vespilloides. Behavioral 622 Ecology. 20(6):1274-1281. doi:10.1093/beheco/arp132.

623 Weimerskirch H. 1992. Reproductive Effort in Long-Lived Birds: Age-Specific Patterns of 624 Condition, Reproduction and Survival in the Wandering Albatross. Oikos. 64(3):464. 625 doi:10.2307/3545162.

626 Weladji RB, Loison A, Gaillard J-M, Holand $\varnothing$, Mysterud A, Yoccoz NG, Nieminen M, Stenseth 627 NC. 2008. Heterogeneity in individual quality overrides costs of reproduction in female 628 reindeer. Oecologia. 156(1):237-247. doi:10.1007/s00442-008-0961-x. 
bioRxiv preprint doi: https://doi org/10.1101/2021.09.08.459445. this version posted September 9, 2021. The copyright holder for this preprint (which was not certified by peer review) is the author/funder, who has granted bioRxiv a license to display the preprint in perpetuity. It is made available under aCC-BY-NC-ND 4.0 International license.

629 Whelan S, Strickland D, Morand-Ferron J, Norris DR. 2016. Male experience buffers female 630 laying date plasticity in a winter-breeding, food-storing passerine. Animal Behaviour. 631 121:61-70. doi:10.1016/j.anbehav.2016.08.014.

632 Wiebe KL. 2018. Age-related improvements in fecundity are driven by the male in a bird 633 with partially reversed sex roles in parental care. Oecologia. 188(4):1095-1104.

634 doi:10.1007/s00442-018-4286-0.

635 